\title{
The analysis of deflections and cracking resistance in pre-stressed slabs of off- shuttering formation
}

\author{
Denis Panfilov ${ }^{1 *}$, Irina Piskareva ${ }^{1}$ and Julia Fomina ${ }^{1}$ \\ ${ }^{1}$ Samara State Technical University, Institute of Architecture and Civil Engineering, \\ Molodogvardeyskaya str. 194, 443001 Samara, Russia
}

\begin{abstract}
The paper presents an example of calculations of an assembled reinforced concrete hollow core slab of off-shuttering formation which has been reinforced with pre-stressed wire in its top and bottom areas. The numerical modelling of statically determinate pre-stressed assembled reinforced concrete hollow core slab exposed to short duration uniform loading is shown as a finite element model in PC "LIRA SAPR 2014 R3". This article contains information about the finite elements used, fixing conditions of the slab and of the order in which links between concrete and steel reinforcement were modelled. The calculation results are presented in the form of isofields of finite elements motion in this calculation model. Table 1 presents research results as a finite element model calculations according to the methodology given in specification documents.
\end{abstract}

\section{Introduction}

Assembled pre-stressed hollow-core slabs of off-shuttering formation (SSF) are widely used in building construction. The reasons for that lie in their advantage in manufacturing technology; in the possibility of covering comparatively big spans (up to $12 \mathrm{~m}$ ); in economic use of materials and in the possibility of architectural re-planning of apartments. Their main peculiarity is the absence of crosswise reinforcement in vertical ribs, as well as the increased hardness due to use of pre-stressed steel reinforcement both in the low and in the top zones.

At the moment there are no specification documents in Russia regulating issues of design and calculation of slabs of off-shuttering formation. EN 1168-2012 [1] gives some recommendations of such slabs design. It is somehow not possible to use formula given in these recommendations as we didn't manage to find coherent coefficients there. Besides, the suggested methodology differs greatly from methodologies used by Russian standards. It is recommended to calculate these structures using SP 63.13330.2012 [2]. But since this regulation does not include requirements for calculation of such specific constructions as hollow core slabs, it also raises a number of questions concerning both modeling these products and peculiarities of their work at all stages of their life cycle, especially their service limit state.

*Corresponding author: panda-w800i@yandex.ru 


\section{Main Part}

This paper continues previous research [5-16] and aims to analyze the existing methodology of calculating deflections and cracking resistance in SSF [2, 18[, to introduce an algorithm for calculating SSF in their service limit state using Mathcad 15 nonlinear deformation model $[20,21]$, to model SSF in PC "LIRA SAPR 2013» and to compare the obtained results.

For theoretical calculations we took a slab with $220 \mathrm{~mm}$ section height, $3580 \mathrm{~mm}$ length, $1500 \mathrm{~mm}$ width (see Figure 1).

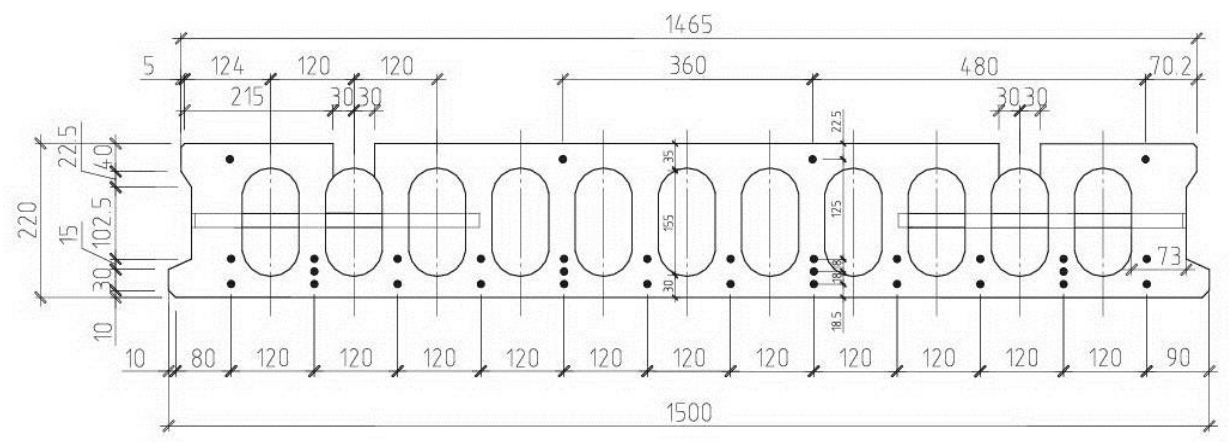

Fig. 1. Cross section of the slab and its reinforcement.

Samples are made of B25heavy concrete with the following mechanical strength characteristics: $\mathrm{R}_{\mathrm{bn}}=18.5 \mathrm{MPa} ; \mathrm{R}_{\mathrm{btn}}=1.55 \mathrm{MPa}$.

The floor slab panel here is reinforced at the top (4Ø5) and bottom (28Ø5) zones with high tensile steel wire (GOST 7348 Vr1400 [3]), with the following strength and deformation characteristics: $\mathrm{R}_{\mathrm{sn}}=1400 \mathrm{MPa} ; \mathrm{E}_{\mathrm{s}}=2 \times 105 \mathrm{MPa}$.

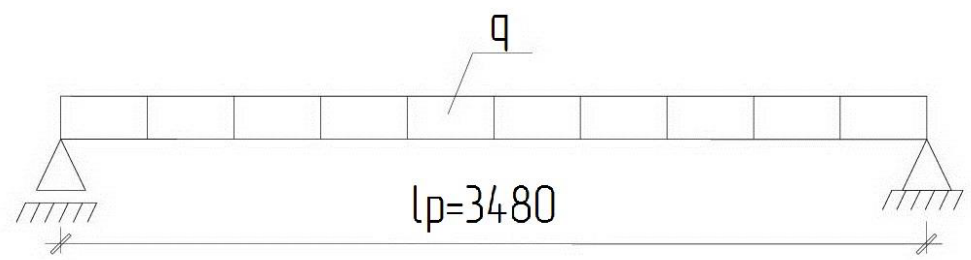

Fig. 2. Design model.

This floor slab panel is design to be used under uniformly distributed loads (in excess of its own mass) $-15,7 \mathrm{kN} / \mathrm{m}^{2}$. The maximum possible load for the construction equals 44.0 $\mathrm{kN} / \mathrm{m}^{2}$.

In our calculations prestressing first and second losses were taken into account. Thus, final values of reinforcement tension were as follows: $720.0 \mathrm{MPa}$ in the lower zone, 720.0 $\mathrm{MPa}$ in the upper zone.

The calculation was made on the stages of manufacture, transportation and use according to SP 63.13330.2012 [2] and a guidebook to SP-102 52-2004 [4].

Deflections of prestressed steel elements which have no cracks in concrete tensile zones are calculated as for an elastic body with rigidity, equal to the product of the modulus on the 
moment of the transformed section inertia. Calculation for areas with no cracks is made according to Formula 9.42 [2].

Loading of the structure was done in a stepwise fashion. The choice of control points is based on the terms of logging. Each stage does not exceed $10 \%$ of the reference load when checking strength and deformation.

Calculation results are given in Table 1.

Simulation of pre-stress condition was performed in PC "LIRA SAPR 2013» by means of temperature exposure.

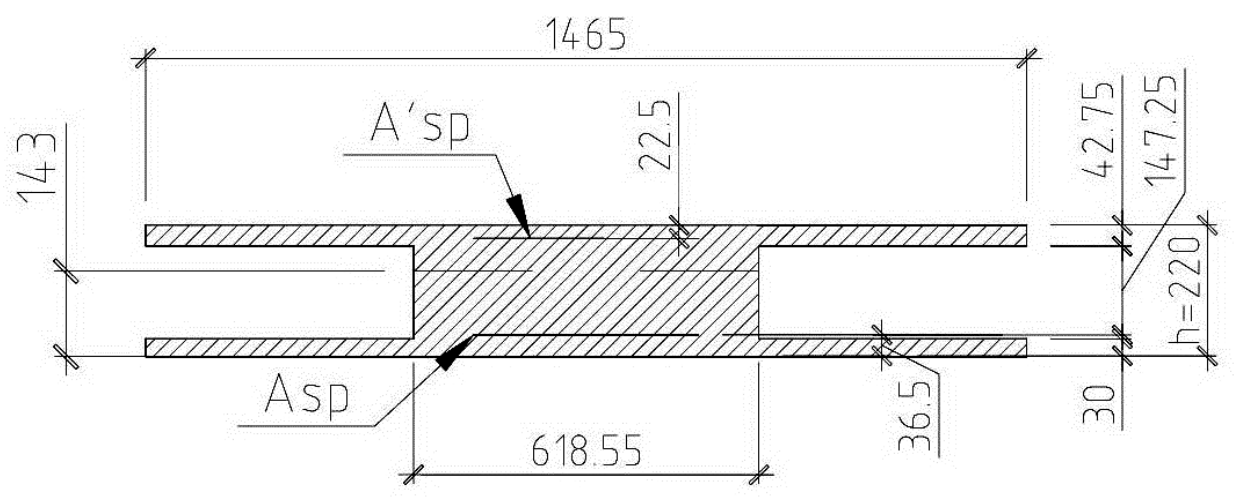

Fig. 3. The transformed section of a slab for calculations in its service limit state.

The slab is modeled with the use of core finite elements as a statically determinate bar in which two rows of pre-stressed high-strength wire were replaced by core finite elements equivalent in terms of area. The joint work of concrete and reinforced finite elements was modeled by the introduction of rigid inserts.

The construction was loaded as follows:

- uploading 1 - its own weight + uniformly distributed load;

- uploading 2 - with allowance for pre-stressed compressed (top) steel reinforcement;

- uploading 3 - with allowance for pre-stressed stretched (bottom) steel reinforcement;

It is not possible to choose proper value of temperature exposure for modelling prestressed condition of the whole structure as we do not yet know flexibility of all the elements in the reference direction. Therefore, at first we set arbitrary initial temperature and calculated the construction to obtain the value of the longitudinal effort in the stressed element. As efforts in the stressed cores under thermal effects are opposite to the efforts of prestressing, the calculation for the specified thermal effects was performed as for a separate uploading.

Automatic calculation results are given in Table 1. 


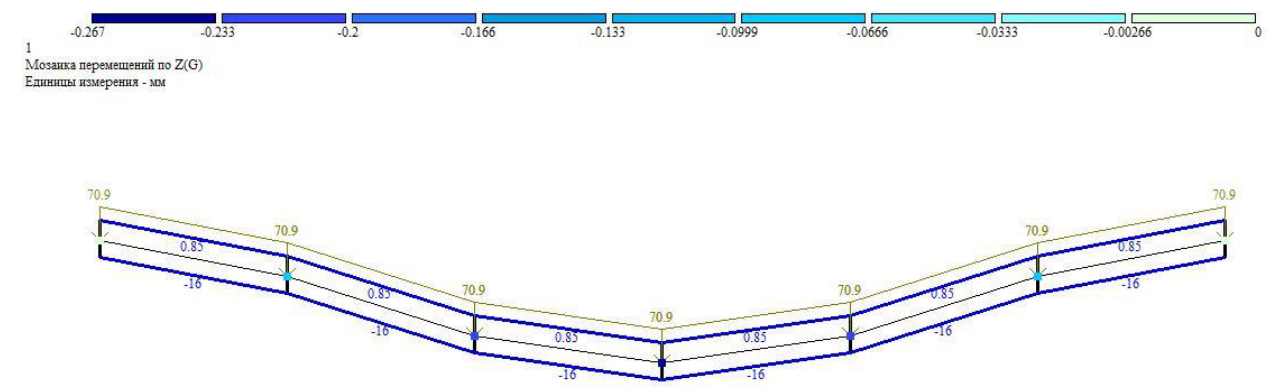

Fig. 4. Mosaic of movement along $\mathrm{Z}$ at maximum loading.

Table 1. The results of the study.

\begin{tabular}{|c|c|c|c|c|}
\hline \multirow{2}{*}{$\begin{array}{c}\text { Loading } \\
\text { No }\end{array}$} & \multirow{2}{*}{$\begin{array}{c}\text { Load applied, } \\
\mathbf{k N} / \mathbf{m} 2\end{array}$} & \multicolumn{2}{|c|}{ Amount of deflection, mm } & \multirow{2}{*}{$\begin{array}{c}\text { Crack width, } \\
\text { mm }\end{array}$} \\
\cline { 3 - 4 } & & $\begin{array}{c}\text { according to } \\
\text { SP 63.13330.2012 }\end{array}$ & $\begin{array}{c}\text { PC } \\
\text { "LIRA SAPR 2013» }\end{array}$ & \\
\hline 0 & Own weight & -0.977 & -1.17 & - \\
\hline 1 & 4 & -0.518 & -0.952 & - \\
\hline 2 & 8 & -0.059 & -0.83 & - \\
\hline 3 & 12 & 0.400 & -0.708 & - \\
\hline 4 & 16 & 0.859 & -0.586 & - \\
\hline 5 & 20 & 1.318 & -0.464 & - \\
\hline 6 & 24 & 1.776 & -0.343 & - \\
\hline 7 & 28 & 2.235 & -0.221 & - \\
\hline 8 & 32 & 2.694 & -0.108 & - \\
\hline 9 & 36 & 3.153 & 0.023 & - \\
\hline 10 & 40 & 3.612 & 0.145 & 0.041 \\
\hline 11 & 44 & 6.854 & 0.267 & \\
\hline
\end{tabular}

\section{Conclusion}

Thus, according to the obtained data, we can conclude that the methodologies we analyzed show dramatic difference in results. It seems incorrect to carry out comparative analysis here.

Numerical modeling of pre-stressed slabs in a linear supply in PC "LIRA SAPR 2013» does not make possible to obtain pre-stressed state realization typical for such a structure. This multiparametric task can only be solved when using more complex software systems. It should also be noted that according to the results of calculations the slab has shown itself as a design that works without cracks in the extended zone, which is characterized by high rigidity of the element. In our further research we plan to perform non-linear numeric modeling and to test prototype samples to compare practical and empirical results. As a result we also plan to to introduce a refined methodology for calculating pre-stressed slabs of off-shuttering formation under uniformly distributed load with account of crack formation and nonlinear work of concrete. 


\section{References}

1. STB EN 1168-2012. Standards of Belarus, "Reinforced assembled units. Hollow core slabs" (2012)

2. SP 63.13330.2012. Concrete and reinforced concrete structures. Fundamental principles. Revised edition. SP 52-101-2003 (2012)

3. GOST 7348-81. Carbon steel wire used for reinforcement of pre-stressed reinforced concrete structures. Specification (1981)

4. Handbook on design of pre-stressed concrete structures of heavy concrete (for SP-102 52-2004) (2004)

5. D.A. Panfilov, N.A. Borodachev, Trad. and inn. in arch. and civ. eng., 70th All-Russia conf. proc., Samara State Un. of Arch. and Civ. Eng. 2, 314-316 (2013)

6. D.A. Panfilov, E.N. Khudyaev, Act. Prob. of arch. and civ. eng. Int. sc. pract. conf.proc., 9-14 (2014)

7. D.A. Panfilov, A.A. Pischulev, Proc. Eng. 111, 626-631 (2015)

8. D.A. Panfilov, A.A. Pischulev, V.V. Romanchikov, Proc. Eng. 153, 531-536 (2016)

9. D.A. Panfilov, G.V. Murashkin, N.A. Borodachev, Trad. and inn. in arch. and civ. Eng., 69th All-Russia conf. 2, 320-322 (2012)

10. D.A. Panfilov, A.A. Pischulev, Proc. Eng. 111, 619-625 (2015)

11. G.V. Murashkin, V.G. Murashkin, D.A. Panfilov, Herald of Volga-region Dep. of Russian Academy of Arch. and Civ. Eng. 14, 144-150 (2011)

12. V.G. Murashkin, D.A. Panfilov, A.I. Snegireva, Trad.s and inn. in arch.and civ. eng., 69th All-Russia conf. proc., Samara State Univ. of Arch. and Civ. Eng., 311-315 (2012)

13. D.A. Panfilov, V.G. Murashkin, Traditions and innovations in architecture and civil engineering, 70th All-Russia conference proceedings 2, 311-314 (2013)

14. V.G. Murashkin, D.A. Panfilov, A.A. Suvorov, Traditions and innovations in architecture and civil engineering, 70th All-Russia conference proceedings 2, 307-308 (2013)

15. G.V. Murashkin, D.A. Panfilov, V.G. Murashkin, Vestnik VolgGASU, 31(50), 388$391(2013)$

16. G.V. Murashkin, V.G. Murashkin, D.A. Panfilov, Int. Jour. for Comp. Civ. and Str. Eng. 8(4) 89-95 (2012)

17. Yu.V. Veruzhsliy, V.I. Kolchunov, M.S. Barabash, Yu.V. Genzerskiy, Computer technologies in designing reinforced concrete structures. Coursework engineering design (2006)

18. S.V. Bosakov, Civil engineering: science and practice, scientific and technical journal pub. by the Ministry of architecture and civil engineering of Belarus Republic 6, 41-46 (2010)

19. A.S. Gorodetskiy, V.S. Shmukler, A.V. Bondarev, Information technologies in calculations and design of building constructions, (NTU HPI, 2003)

20. D.S. Toshin, Town-planning, reconstruction and engineering support of Povolzhje cities and towns sustainable development, All-Russia conference proceedings, 312-313 (2004)

21. D.S. Toshin, Town-planning, reconstruction and engineering support of Povolzhje cities and towns sustainable development, II All-Russia conference proceedings, 224229 (2009) 